\title{
What is Missing in Biosphere Reserves Accountability?
}

\author{
Reinaldo Lourival ${ }^{1,2 *}$, Matt Watts ${ }^{3}$, Robert Leslie Pressey ${ }^{4}$, Guilherme de Miranda Mourão5, \\ Carlos Roberto Padovani ${ }^{5}$, Marta Pereira da Silva ${ }^{5}$ \& Hugh Phillip Possingham ${ }^{3}$
}

\author{
${ }^{1}$ Wildlife Conservation Society, Brazil Program, Brasília, DF, Brazil \\ 2 The Capes Foundation, Ministry of Education Brazil, Brasília, DF, Brazil \\ ${ }^{3}$ University of Queensland, The Ecology Centre - St. Lucia, Brisbane, Australia \\ ${ }^{4}$ James Cook University, ARC Centre for Coral Reef Studies, Townsville, QLD, Australia \\ ${ }^{5}$ Empresa Brasileira de Pesquisa Agropecuária, CPA Pantanal, Corumbá, MS, Brazil
}

\begin{abstract}
The design of Biosphere Reserves (BR) poses an interesting problem for systematic planning. It entails a spatially explicitly compromise between economic, social, cultural and biodiversity protection objectives, in a sustainable development context. The global network of Biosphere Reserves includes 563 sites in 110 countries. Currently the spatial configuration of BRs follows a nested scheme, where different land use regimes are assigned to zones in an ad hoc fashion, which complicates the evaluation of their effectiveness. So far in the literature, have not been designed to achieve quantitative objectives, which could limit their value for sustainable development. Using the newly developed version of the software MARXAN ${ }^{\odot}$, we solve part of this problem enabling BRs to reach predefined set of spatially explicit quantitative targets, while minimizing the reserves' overall costs (i.e. opportunity, implementation, land value, etc.). Our case study is the Pantanal Biosphere Reserve (PBR), in Brazil. According to our results the PBR could substantially improve its effectiveness if a systematic review of its objectives and goals is performed. Rearrangements of all zones proved to be necessary. Core zones for example, composed of IUCN categories I to IV, increased from its current $1.5 \%$ of the BR area to $18.5 \%$ to reach all objectives. The absence of quantitative guidelines from UNESCO for the configuration of BRs has limited their effectiveness. Our quantitative systematic approach provided the first insights into potential requirements for zone partitioning, prescribing $22 \pm 5 \%$ to be allocated in core zones, $22 \pm 3 \%$ in buffer zones, and $33 \pm 4 \%$ in transition zones. The most useful outcome, however, was the flexibility the software offered to reach multiple objectives simultaneously.
\end{abstract}

Key words: Zoning, Systematic Planning, Pantanal Wetland, Conservation, UNESCO-MAB, MARXAN for Zoning.

\section{Introduction}

Biosphere Reserves (BRs) were introduced into the conservation arena in the late sixties almost concomitantly with the launch of United Nation's Man and the Biosphere Program (MAB-UNESCO). They were conceived as a "way to a more sustainable future" or "spaces to reconcile people and nature" (UNESCO 2002). They represent the concerns of the United Nations to secure the protection of natural diversity while maintaining the cultural heritage of traditional communities. This concept is intended to be implemented through a network of reserves representative of all ecosystems that should serve as models of "sustainable societies" and sustainable development (Batisse 1990). The current network includes 529 sites in 105 countries (UNESCO 2002, 2007), six of them located in Brazil.

\footnotetext{
${ }^{\star}$ Send correspondence to: Reinaldo Lourival

Wildlife Conservation Society - Brazil Program, SHIS-QI 05-

Bl, F-Sala 101, Lago Sul, CEP 7165-560, Brasilia, DF, Brasil

e-mail: r.lourival@gmail.com
}

The BR zonation model evolved with little guidance, based on a three-zone nested scheme, popularized as the "egg model" (Figure 1), with a core nucleus, a buffer and a transition zone. The criteria/guidelines for the establishment of BRs were initially defined in the Seville strategy (Poore 1995), which addressed the functional objectives of BRs (i.e. biological and cultural diversity, sustainable development and logistical role) through four objective-oriented tasks (UNESCO 1995):

- Use BRs to protect and conserve natural and cultural diversity;

- Utilize BRs as models for sustainable development;

- Use BRs as logistic support for research, monitoring, educational and training;

- Fully implement the concepts of BR, through the harmonization of the above functions. 
The spatial configuration of BRs, based on "the egg" (Figure 1), have core areas, which are necessarily strict reserves (IUCN categories I - IV) which are nested within buffer zones that allow some direct use of biodiversity. The buffer is then surrounded by a transition zone, which accommodates a broader array of land uses, including agriculture, urban centers and other more intensive land uses (Dasmann 1988; UNESCO 2002). When the BR model was conceived, the key principles of systematic conservation planning were not yet developed and the accountability of BRs or the role of each zone in meeting specified goals could not be tested (Possingham et al. 2006).

Currently, however, the UNESCO-MAB is revising the goals and objectives of BRs in order to provide more objectivity for the BR model. Their aim is to review the framework of the BR in order to address the challenges of fragmentation and the effects of climate change. The Madrid congress (MAB Program 2008) aimed to substantially improve the BR model in four components: adaptive governance, zonation, science and capacity building and partnerships. However a review of the proposed Action Plan overlooks the key principles of Comprehensiveness, Adequacy, Representation and Efficiency known by the acronym CARE (Possingham et al. 2006), which is central to systematic conservation planning and essential for accountability of BRs. Therefore, systematic planning for BRs, needs to integrate qualitative and quantitative tradeoffs between objectives within and between zones (Batisse 1997; Rosova 2001), while providing quantitative assessment of target achievement (i.e. biodiversity, socio-cultural and economic sustainability).

The Pantanal BR was developed in an ad hoc process (i.e. non systematic), based on expert opinion, as a result of the National Biodiversity Program-PROBIO (Brasil 1999).
Although there second round of priority setting workshops (Brasil 2007), although using principles of systematic planning, as never integrated into the Brazilian BRs system. For example, there were mentioning of indigenous territories and other key historical and biodiversity sites from the current PBR map (e.g. enduring rockeries, archeological sites and fortresses from the Paraguay war or even memorials of the Pantaneiro ranching history).

\section{Zoning in the Context of Systematic Conservation Planning}

According to Possingham et al. (2006) systematic conservation planning involves finding the best set of potential areas to be protected, while satisfying a number of principles (e.g. comprehensiveness, representativeness, adequacy, efficiency), while providing flexibility, risk avoidance, and an metric for site irreplaceability. Systematic zoning aims to go a step further and help mainstream the principles of systematic planning to other sectors of society including traditional landholders, agriculturalists and even the urban centers. However, in order to accomplish this, planners will have to face challenges that go beyond the realm of biodiversity with even more controversial and scarce socio-cultural datasets (Schoemaker 1991; Gaston \& Rodrigues 2003).

Zoning has been used in urban planning and conservation for a long time (Werner 1926; Ukeles 1964) and not surprisingly shares the same ad hoc characteristics observed in non-systematic reserve design (Pressey 1994), except that different zones cover a wider range of land management regimes (from strict reservation to intensive agriculture and urban development). Therefore, zoning has the potential to incorporate the contribution of reserved and

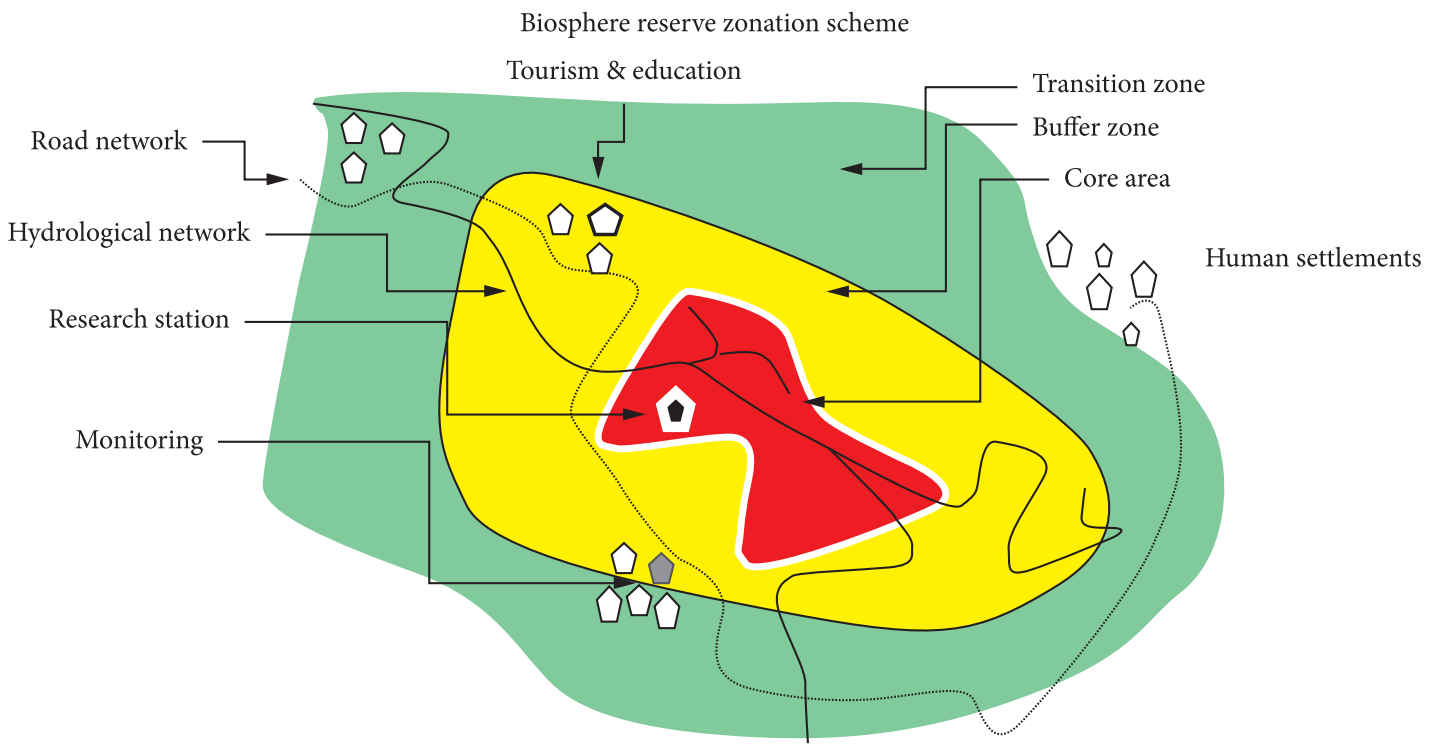

Figure 1. Basic configuration of a Biosphere Reserve, based on the egg model for core, buffer and transition zones (red, yellow and green respectively). 
non-reserved areas not only to biodiversity conservation but to a broader set of objectives within a more realistic planning framework.

Systematic zoning of BRs needs to be data driven, goal oriented, efficient, spatially explicit, transparent, flexible and inclusive (Pressey 1999). Only recently, however, did investigation into systematic zoning begin (Moilanen et al. 2005) enabling planning for multi-objective, multistakeholder contexts (Wilson et al. 2010). Forest managers used simulated annealing to harmonize site suitability and different forestry regimes (Bos 1993) and Verdiell \& Sabatini (2005) Sabatini \& Verdiell (2007) internally zoned a protected area designated as a world heritage site in Argentina. Howevers in both cases, the claims of spatially explicit zoning were based only on spatial attributes such as compatibility and connectivity. They overlooked the explicit incorporation of objectives in the optimization, failing to explicitly target representation, complementarity and constraints of conflicting objectives in the actual problem definition (Possingham 2001; Wilson et al. 2010).

In this paper we show how systematic zoning could be applied not just as a tool to spatially characterize management schemes, but also to integrate the principles of comprehensiveness, adequacy, representation and efficiency of CARE (Possingham et al. 2006) to BRs. We show how a spatially explicit tool can engage the public into the decision process, where objectives and goals are laid out and compromises are negotiated explicitly (Dhargalkar \& Untawale 1991; Higgins et al. 2004; Cabeza \& Moilanen 2006; Wilson et al. 2010).

\section{The Problem at Hand - the Pantanal Biosphere Reserve Accountability}

The Pantanal Biosphere Reserve (PBR), instated in 2000, extends through 25,156,905 ha of the upper Paraguay River (Figure 2). With a total of 664,245 ha in nine core areas, $5,392,480$ ha in buffer zones and around 19 million ha in transition zones, the PBR spreads through Mato Grosso, Goiás and Mato Grosso do Sul States. A review of Pantanal conservation portfolios by Lourival et al. (2009) found poor representation of important conservation features, lack of socio-cultural consideration and low efficiency, demonstrating the need for a careful re-evaluation of the PBR.

The Upper Paraguay River Basin (UPRB) which contains the PBR, comprises a $365,000 \mathrm{~km}^{2}$ extensive network of rivers and wetlands of great biodiversity importance
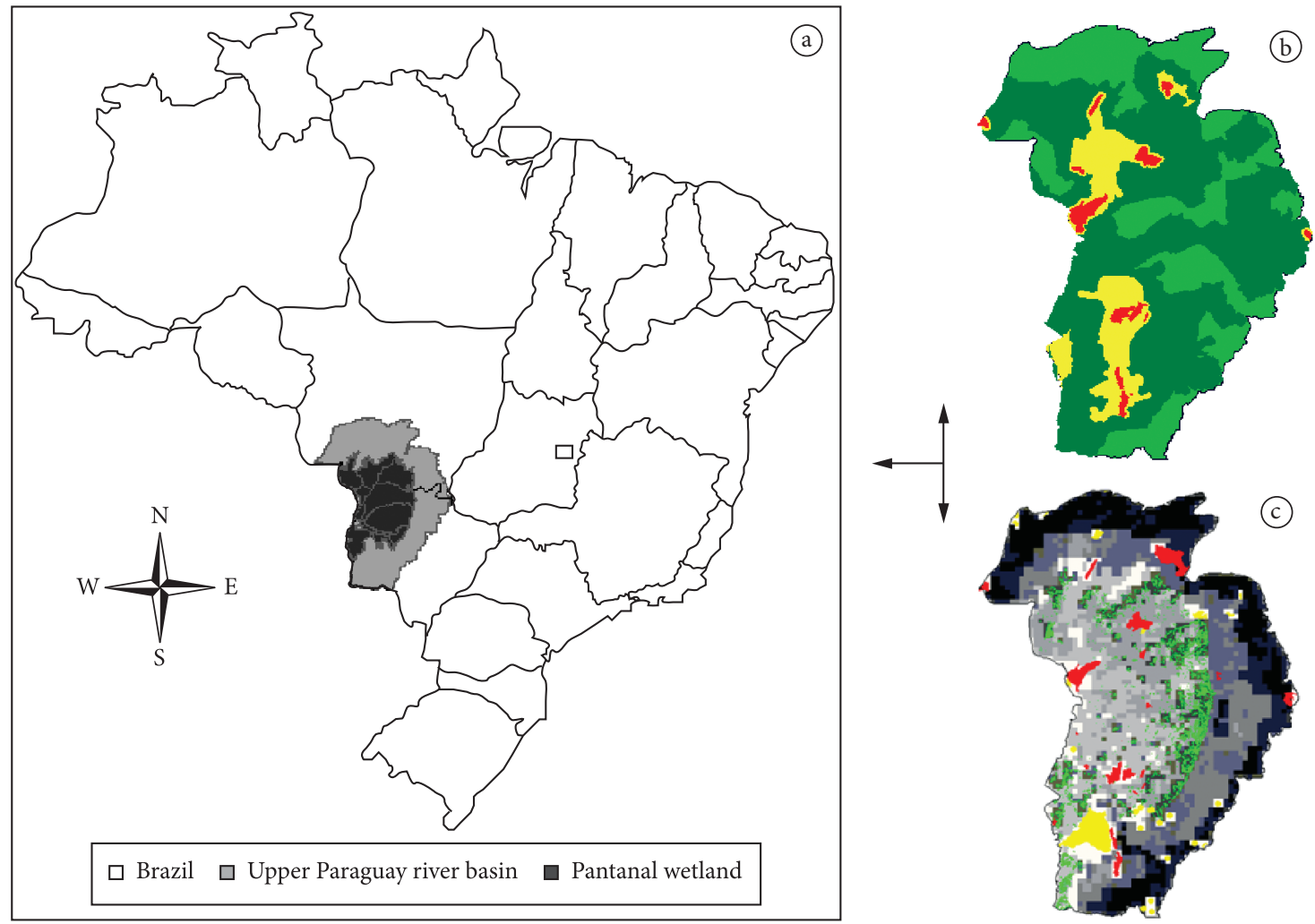

Figure 2. Pantanal location in Brazil (a) and the map of the Pantanal Biosphere Reserve (ad hoc scenario), (b) where red represents core areas, yellow indicates buffer zones and dark green is the transition zone. Light green refers to areas within the boundary of the Upper Paraguay River Basin that were not included in the original ad hoc plan. Average acquisition cost surface for the UPRB, extracted from Lourival et al. (2008). Costs were scaled in 14 gray scale classes (c). Existing protected areas are represented in red, indigenous territories in yellow and areas deforested in light green (Padovani et al. 2004). 
(Higgins et al. 2005). The Pantanal is shared by Brazil (70\%), Bolivia and Paraguay (30\%) (Assine \& Soares 2004). The Pantanal is under pressure from agricultural encroachment, expansion of primary industry and large investments in energy and transportation infrastructure (Junk \& Nunes da Cunha 2005). The outcomes of such threats can be easily identified in and around the Pantanal wetland by the rates of conversion of natural habitats, the accelerating erosion of headwaters, and siltation in the floodplain (Veneziani et al. 1998; Wantzen 2003; Padovani et al. 2004).

\section{The MARXAN Decision Support Tool}

MARXAN with Zones is a new development (Watts et al. 2009) of the widely used reserve design software MARXAN (Ball \& Possingham 2000). It represents a paradigm shift in conservation planning thinking towards a multi-objective scheme that allows planning of several management/land use regimes. MARXAN with Zones generalizes MARXAN's formulation by increasing the number of states or zones to which a planning unit can be assigned. These assignments are conducted to maximize the planning unit efficiency, across a range of objectives (Possingham et al. 2000), optimizing the compromises between site suitability and availability in the context of variable costs. The software allocates planning units to zones to achieve an agreed set of targets using simulated annealing and iterative improvement algorithms, according to the mathematical formulation described by Watts et al (2009).

\section{Guaranteeing Accountability for Biosphere Reserves}

Our aim was to provide a framework and guidelines to systematically zone BRs, comparing the representation, comprehensiveness and spatial configuration of an ad hoc and systematically designed PBR. We used six scenarios (see zone juxtaposition in Methods), to illustrate the capacity and flexibility of MARXAN with Zones in order to: evaluate existing BRs, support the design of new reserves, and help the rezoning process of existing reserves under the principles of systematic planning.

We used the principles of the Madrid Action Plan (MAB Program 2008), but supported by the principles of systematic planning (Possingham et al. 2006) which is in the official Action Plan. We specifically wanted to respond to two questions related to the BR model: 1) how to optimize spatially explicit compromises of representation under a multi-zone and multi-objective context?; and 2) what capabilities of MARXAN with Zones can be useful to handle the spatial constraints of zonation of BRs, to assure their accountability?

Regrettably, we could not find in the literature any quantitative indicators or formally prescribed targets for any of the zones of BRs. The guidelines contained in the Madrid Action Plan (MAB Program 2008) state that every zone should contribute simultaneously to the achievement of the biodiversity, socio-cultural and sustainability objectives of a BR. This provides us with a crude idea of how we can do zoning systematically.

Targeting biodiversity, socio-cultural and economic features in a multi-objective scheme allowed control of the tradeoffs between feature representation and complementarity between zones within the same reserve. It also provided an opportunity to regulate the spatial distribution of features only to suitable zones (principle of permissibility), avoiding spatial juxtaposition of incompatible land-uses. We explored, in some detail, the spatial compatibility between management regimes while assigning planning units to specific zones of the PBR (e.g. indigenous reserve versus agribusiness).

We intend our solutions to support the biodiversity, sociocultural and sustainability and logistic roles of BRs (UNESCO 2002). The zoning problem as previously defined is solved by MARXAN with Zones, allowing for spatially explicit trade-offs between these objectives for BRs. Comparing the existing map with the proposed new spatial configuration, we aim to provide MAB UNESCO with some methods for using systematic conservation planning principles in BR planning.

\section{Our General Protocol}

This section describes the planning framework, the problem formulation and information layers used in systematic zoning, as well as the data treatments necessary to parameterize MARXAN with Zones. Later, we explore the sensitivity of the software to parameters such as zone compatibility, representation targets and costs. Finally, we describe the scenarios we used to redesign the PBR based on a multiobjective framework, exploring the potential of MARXAN with Zones for planning BRs in general.

\section{Planning framework for the Pantanal Biosphere Reserve}

For this case study, the area under analysis encompasses not only the territory designated to the PBR but the whole UPRB in Brazil (Figure 2). This watershed was divided into a grid with 3727 planning units, each one with an area of 10,000 ha. We used 293 features including 117 modeled species distributions, environmental features such as soil, distance to rivers and vegetation, and socio-cultural elements such as indigenous land and traditional ranching. The features were systematically structured to provide representation and complementarity between the core, buffer and transition zones.

We searched for the most efficient spatial configuration for the PBR. The MARXAN with Zones algorithm was able to freely select and allocate planning units according to their contribution they provided to targets. 


\section{Problem formulation for multiple objective zoning constrained by multiple costs}

Heuristic algorithms have been the method of choice to efficiently achieve biodiversity feature representation in systematic conservation planning (Possingham et al. 2000; ReVelle et al. 2002). Nevertheless, zoning as assumed by the BR model offers extra complexity to systematic planning for two reasons: (a) each management regime and land use offers differential contribution to targets (MAB Program 2008; Watts et al. 2009); and (b) each land parcel, when allocated to a particular zone, has a variable cost structure (i.e. acquisition, management and maintenance), both affecting the way in which efficiency of reserve systems is measured (Pressey \& Nicholls 1989).

The traditional formulation of the objective function used by MARXAN (Ball \& Possingham 2000) to optimize site selection under the minimum set coverage problem can be summarized by the expression:

- Minimize the cost of the reserve system + Boundary cost + Feature representation shortfall penalty.

The objective function according to Watts et al. (2009) is now written as:

- Minimize the configuration costs of all zones + Boundary compatibility cost + Feature and zone representation shortfall penalty.

Boundary compatibility cost is a weight imposed to avoid incompatibility between zones, which is minimized by MARXAN in the objective function.

\section{Target setting}

In all 6 proposed we aimed to represent 293 features, ranging from soils classes to species occurrences models and wildlife densities, in all three zones. Features such as vegetation, freshwater eco-domains, and watersheds, were targeted based on the minimum $20 \%$ representation of the Brazilian forestry code and the rarity of these features (Lourival et al. 2009). Targets for wildlife and cattle densities that are culturally and economically valuable were set at $30 \%$ for each zone.

It is important to emphasize, however, that the target values from PROBIO workshops were proposed under the assumption that the presence of features outside strict reserves did not provide any contribution towards conserving them. This assumption is not reasonable or appropriate since the presence and maintenance of genes, species and processes associated with biodiversity are not exclusive to protected areas (Negi \& Nautiyal 2003; Wallington et al. 2005; West et al. 2006).

We aimed for feature representation in three ways. First we used the traditional feature targets for 293 features (e.g. species, vegetation, indigenous territories). For species representation we used the same targets as proposed by the PROBIO priority setting workshop and aimed to represent the number of occurrences, or percentage of the total area to be achieved, across all zones. Then we used the "zone target" for 37 features, which specifies the minimum representation necessary of a feature amount required in each one of the three zones of the PBR. Finally, assuming different zones make different contributions to a feature, we set the values for zone contribution to 292 features expressing the differential capability of each zone to maintain each feature (Table 1 ).

For data layers where features had spatially variable density such as the aerial survey data for cattle, caimans, capybaras, marsh and pampas deer (Mourão et al. 1994, 2000), we set specific zone targets. For example, we set targets for low and medium cattle densities specifically to buffer zones in the floodplain, assuming that they contribute to an important cultural attribute of the Pantanal. On the other hand, planning units that had high cattle densities were assigned to transition and available planning units that were not selected by the software zones, with the purpose of achieving ranching sustainability goals throughout the watershed.

According to the BR model, core zones consist of areas designated as strict reserves (i.e. IUCN categories I to IV), which are protected by buffer zones that allow traditional (low impact) land use practices. The transition and available zones allow for more intensive land use practices. Transition zones, however, also need to comply with the sustainability goals, while available planning units are not necessarily included in such a management scheme. Based on such restrictions we set feature-by-zone contribution to targets, as mentioned above. We used these measures to systematize the level of protection each zone provides to a feature, defining the level of use permitted in a zone (i.e. permissibility). This value can be used as well as a measure of the likelihood of the persistence of a feature in a zone. The values attributed to each feature in each zone (Table 1) reflect the relation between their rarity and vulnerability (Pressey \& Taffs 2001). We illustrate this using the jaguar as an example (Table 1), where one hectare of jaguar territory in core zone provides a contribution equivalent to a hectare to the jaguar target. In a buffer zone, one hectare of jaguar modeled distribution is worth 0.75 of a hectare for the representation target, since the likelihood of persistence in buffer zones is smaller. In transition zones this value is reduced to 0.5 , meaning that 2 ha of jaguar suitable habitat, in transition zones are equivalent of one hectare in the core zone (Crawshaw \& Quigley 1991). Basically the proportions (Table 1) were multiplied by the area of the feature selected in that zone, providing their corrected contribution to the overall feature target (Watts et al. 2009). MARXAN with Zones still can assign planning units to whichever zone improves the overall efficiency, but assumes that the occurrence of a feature of interest in that zone represents a fraction, for example, of its occurrence in more protective zones, which is represented by a specific weight (set by the user) to each zone reflecting how much of the target is met in that zone. 


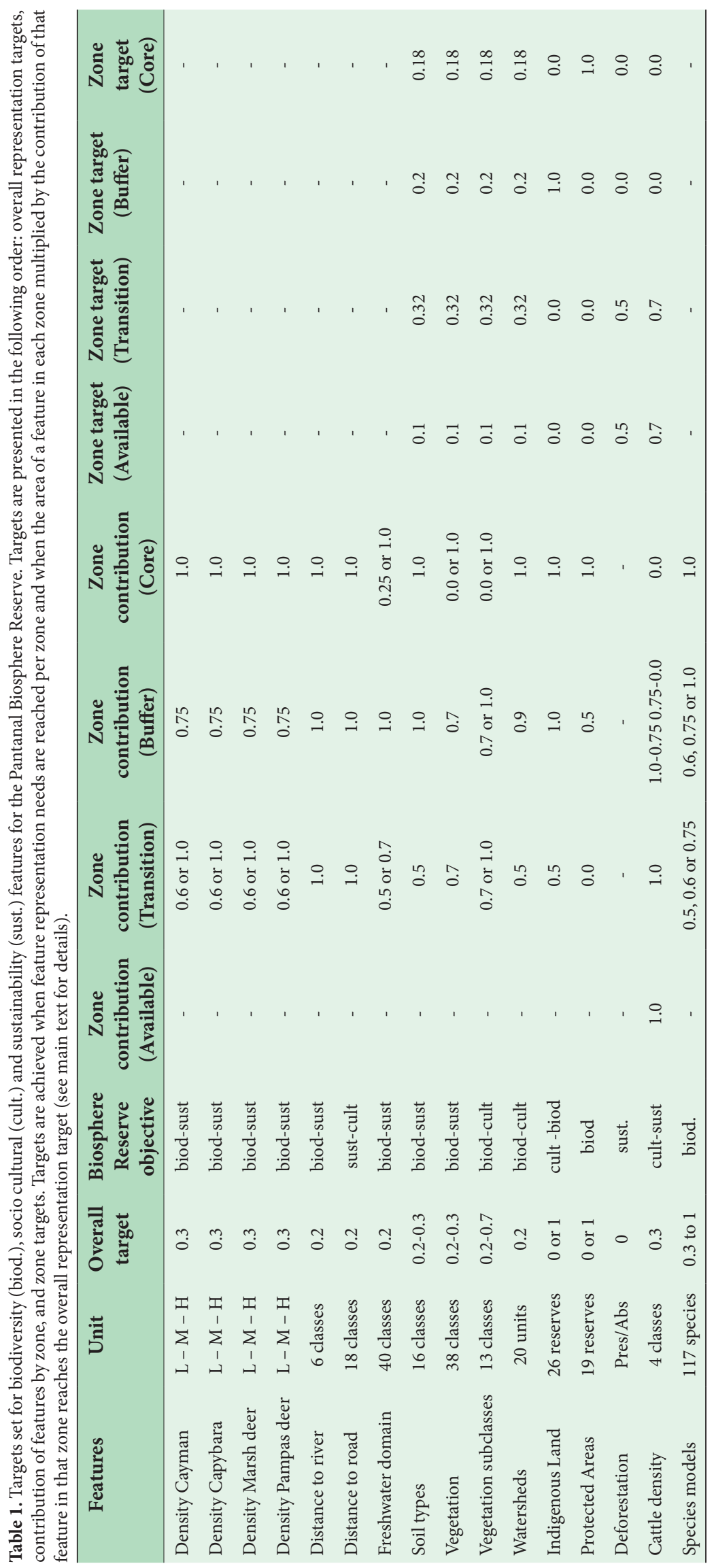




\section{Species models and representation targets}

We modeled the distribution of 117 vertebrate species (Figure 3) using the maximum entropy algorithm in MAXENT software (Phillips et al. 2006). All species were red-listed either by IUCN or by the Brazilian Environmental Institute (IBAMA) and their point occurrences were obtained from the Conservation International database (Brasil 2007). Targets for species were set according to experts appointed by the Brazilian government in the PROBIO prioritization workshop (Brasil 2007). We chose MAXENT because of its advantages over other methods for presence-only data (Elith et al. 2006).

We adjusted these targets to enhance complementarity between zones and account for the differential contribution expected from each of the $\mathrm{BR}$ zones, using the zone contribution weights. The predicted distribution maps were based on presence-only data and the predictive variables were elevation, vegetation, soils, distance to rivers, distance to roads, and fragility, acknowledging, however, the uncertainties associated with species modeling (Loiselle et al. 2003), and the problems associated with omission and commission errors as sources of inefficient resource allocation (Field et al. 2004).

We targeted densities of four species, caimans, capybaras, marsh and pampas-deer (Table 1) based on the results of aerial surveys conducted during the last decade (Mourão et al. 2000). Wildlife densities were chosen due to their correlation with ecosystem productivity (Odum et al. 1995; DeAngelis et al. 1998; Daoust \& Childers 1999), an important ecosystem function to be specifically safeguarded, as a qualitative variable (i.e. low, medium and high for each of the zones).

For the purpose of this analysis we considered that a target was achieved when the overall areas selected contained more than $90 \%$ of the representation requirement. Hence, based on the distinct but complementary characteristics of targets we aimed to achieve explicit representation of quantitative and qualitative features, and to illustrate the importance of target setting to the BR's biodiversity, socio-cultural and sustainability objectives. Despite our efforts to set targets for as many ecological, social and economic features as possible, we believe that a more extensive set of features should be investigated and used for the actual review process. The current study illustrates to BR practitioners how to be accountable for their successes and failures, while providing the "BR model", with an evaluation tool, based on quantitative indicators, capable of addressing the expansion of the UNESCO-MAB program.

\section{Cost layers}

Costs and constraints are an essential part of the optimization process under the minimum set problem formulation. They are a basic component of the objective function and are represented by the cost of planning unit $i$ in zone $k$, as the factors to be minimized, while the algorithm attempts to represent all features at their target levels. Altogether we used 37 independent spatially explicit cost layers. They were used as individual cost layers due to their importance in defining potential land use types, while also aggregated as zone costs.

Acquisition costs are another major component of BR implementation, particularly in core zones. These costs are dynamic by nature, responding to changes in commodity prices and infrastructure (Lourival et al. 2008). We integrated acquisition costs based on the equations proposed in Lourival et al. (2008) for the Taquari catchments and we extrapolated acquisition costs across the entire UPRB. This extrapolation assumed that the behavior of land cost is the same across the entire planning region (Figure 2c).

It is also important to emphasize that some of the layers used as costs were also targeted as features to be represented depending on the zone objective. Certain soil types, for example, are desirable features for achieving sustainability in ranching and agriculture if assigned to buffer or transition zones.

Table 2. Range of values for each cost layer according to the zone a planning unit is assigned to. The values for each zone are weights that are multiplied by the area occupied by the feature cost layer. Abbreviations for BR objectives: biodiversity (biod), socio cultural (cult) and sustainability (sust).

\begin{tabular}{|c|c|c|c|c|c|c|}
\hline Cost layer & BR & Unit & Zone 1 & Zone 2 & Zone 3 & Zone 4 \\
\hline Features & Objective & & Available & Transition & Buffer & Core \\
\hline Cattle density & cult-biod & 4 classes & 0 & 0 & 0 & 100 \\
\hline Deforestation & biod & pres/abs & 0 & 0 & 80 & 100 \\
\hline Distance to river & sust & 6 intervals & 0 & 80 & 50 & 0 \\
\hline Distance to roads & sust & 18 intervals & 0 & 0 & 50 & 10 \\
\hline Erodibility & biod & 4 classes & 0 & 20 & 100 & 100 \\
\hline Fire risk & biod & 13 classes & 0 & 10 & 50 & 70 \\
\hline Fragility & sust & 6 classes & 0 & 0 & 50 & 100 \\
\hline Soil types & sust & 16 types & 0 & $0-100$ & $0-100$ & $0-100$ \\
\hline Vegetation subclasses & cult-sust & 13 types & 0 & $0-100$ & $0-100$ & $0-100$ \\
\hline Acquisition costs & cult-sust & continuous & 0 & 20 & 50 & 1000 \\
\hline
\end{tabular}



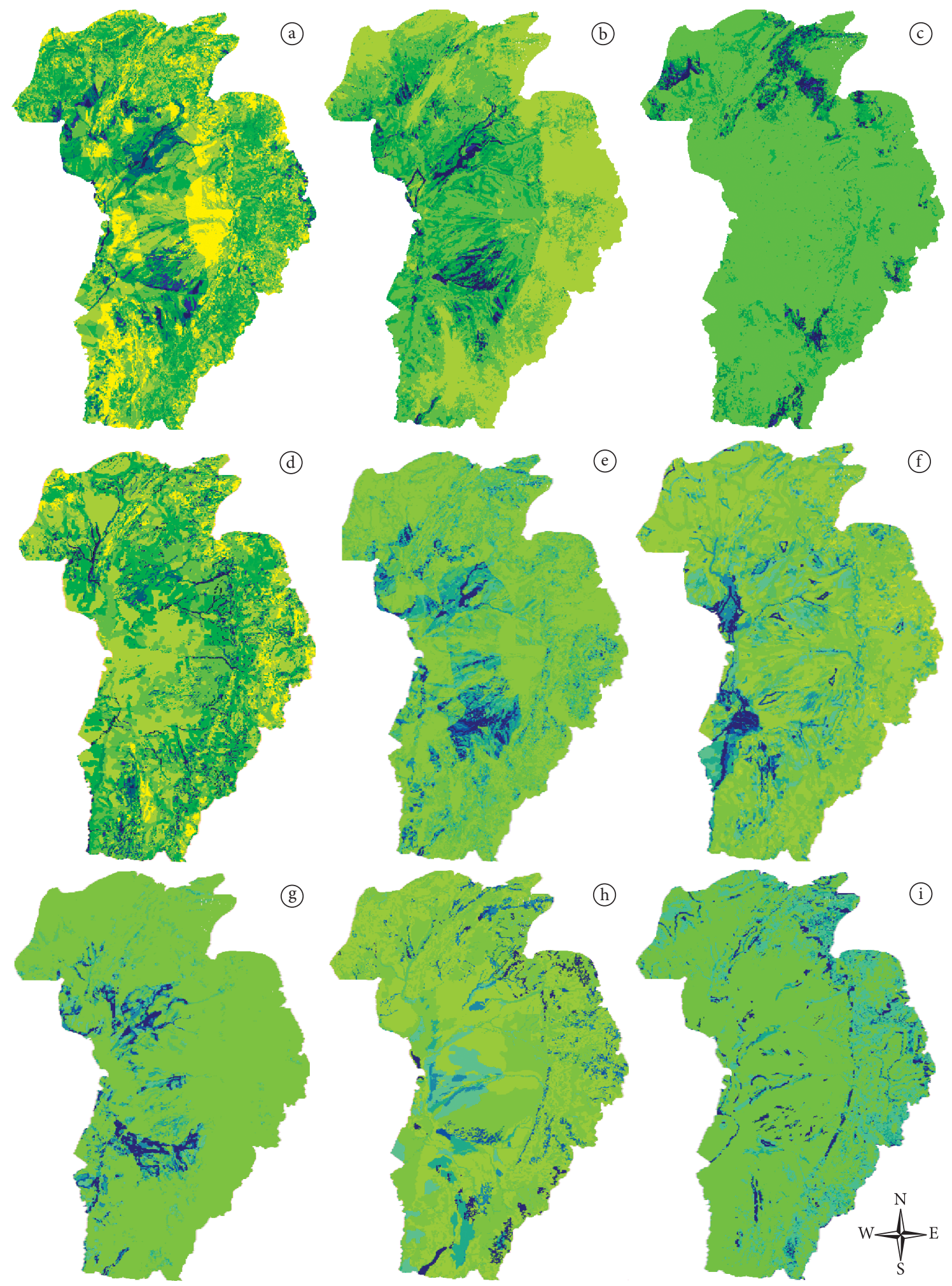

Figure 3. A sample of MAXENT modeled distribution for some PROBIO listed species (i.e. probability of occurrence based on presence only data) of: a) hyacith macaw (Anodorhynchus hyacinthinus), b) marsh deer (Blastocerus dichotomus); c) Amphisbaena (Bronia bedai); d) tortoise (Geochelone denticulata); e) ocelots (Leopardus pardalis); f) mamore arboreal rice rat (Oecomys marmorae); g) giant river otter (Pteronura brasiliensis); h) bush dog (Speothos venaticus); i) crowned eagle (Harpyhaliaethus coronatus). Colors represent a scale from light green (lower) to dark blue (higher) depicted in standard deviation units. 


\section{Connectivity and spatial compatibility between zones (zone juxtaposition)}

The spatial configuration of reserve systems is fundamental to guaranteeing the persistence of species and ecological processes (Gerber et al. 2003; Cabeza et al. 2004). When this idea is expanded to BR zoning, the issue of compatibility between zones (juxtaposition) becomes even more important, because we are negotiating compromises between different land uses. More often than not, some land uses are mutually incompatible and therefore need separation between them. Sometimes connectivity is essential to maintain ecological and socio-economic processes so compatibility is welcome. One interesting capability of the MARXAN with Zones software is that it allows control over the juxtaposition of zones. The use of spatial compatibility allows zones to be nested as the original BR planning process mandates.

We investigated the compatibility between zones in the PBR case study to provide alternative zone configurations based on the BR zonation model. We used the compatibility matrix (Table 3) to evaluate the effect of nestedness on the spatial configuration and to evaluate the flexibility of solutions as suggested in the draft of the Madrid Action Plan (MAB Program 2008). We fixed parameters such as: targets, costs and boundary length in all scenarios, and varied the compatibility values in six scenarios (described below) and evaluated their performances on the basis of compactness and nestedness and efficiency (i.e. least cost maximum representation).

Another parameter that we altered was the status of existing reserves and indigenous territories. In the odd-numbered scenarios, all planning units were available for allocation to any zones, while in the even-numbered scenarios the reserves were preferentially assigned to core areas and indigenous land to buffer zones. The terms "locked" and "unlocked" signify compulsory or optional the presence, respectively, of existing reserves and indigenous land each of the scenarios described below:
- Scenario (1) - total compatibility between planning units in the same zone, but no compatibility between zones existing reserves and indigenous land were optionally available for selection;

- Scenario (2) - total compatibility between planning units in the same zone, and no compatibility between zones. Existing reserves and indigenous land were locked into the analysis. Protected areas were locked into core areas while indigenous lands were locked into buffer zones;

- Scenario (3) - no compatibility between planning units in the same zone and total compatibility between zones. Existing reserves and indigenous land were optionally available for selection;

- Scenario (4) - no compatibility between planning units in the same zone, but total compatibility between zones. Existing reserves and indigenous land were locked into the analysis. Protected areas were locked into core areas while indigenous lands were locked into buffer zones;

- Scenario (5) - compatibility between planning units in the same zone and variable compatibility between zones. Values were set to facilitate nestedness and clumping. In this scenario existing reserves and indigenous land were optionally available for selection;

- Scenario (6) - total compatibility between planning units in the same zone, but variable compatibility between zones. Values were set to facilitate nestedness and clumping. In this scenario existing reserves and indigenous land were locked into the analysis. Protected areas were locked into core areas while indigenous lands were locked into buffer zones.

One output of MARXAN with Zones is the frequency with which each planning unit is assigned to one of the zones. This output is known as selection frequency in

Table 3. Zone compatibility matrix used to explore the compatibility between zones and their juxtaposition. The values under each scenario provide the spatial configuration seen in Figures 4 and 5. The terms locked and unlocked signify the compulsory presence or optional absence, respectively, of existing reserves and indigenous land in each scenario.

\begin{tabular}{cccccccc}
\hline Zone & Zone & Scenario (1) & Scenario (2) & Scenario (3) & Scenario (4) & Scenario (5) & Scenario (6) \\
\cline { 2 - 7 } & & Unlocked & Locked & Unlocked & Locked & Unlocked & Locked \\
\hline 1 & 1 & 0.00 & 0.00 & 1.00 & 1.00 & 0.00 & 0.00 \\
1 & 2 & 1.00 & 1.00 & 0.00 & 0.00 & 0.01 & 0.01 \\
1 & 3 & 1.00 & 1.00 & 0.00 & 0.00 & 0.80 & 0.80 \\
1 & 4 & 1.00 & 1.00 & 0.00 & 0.00 & 0.10 & 0.10 \\
2 & 2 & 0.00 & 0.00 & 1.00 & 1.00 & 0.00 & 0.00 \\
2 & 3 & 1.00 & 1.00 & 0.00 & 0.00 & 0.10 & 0.10 \\
2 & 4 & 1.00 & 1.00 & 0.00 & 0.00 & 0.80 & 0.80 \\
3 & 3 & 0.00 & 0.00 & 1.00 & 1.00 & 0.00 & 0.00 \\
3 & 4 & 1.00 & 1.00 & 0.00 & 0.00 & 0.01 & 0.01 \\
4 & 4 & 0.00 & 0.00 & 1.00 & 1.00 & 0.00 & 0.00 \\
\hline
\end{tabular}


MARXAN (Carwardine et al. 2007). We classified the selection frequency, using the same criteria described by Lourival et al. (2009). The spatial distribution of the selection frequencies (Figures $5 \mathrm{a}-\mathrm{g}$ ), were compared using the Kappa statistic (Monserud \& Leemans 1992), measuring the dissimilarities between scenarios, for each of the zones. The pair-wise comparison of Cohen's kappa was conducted between scenarios (1) and (2), (3) and (4), and (5) and (6) with the purpose of understanding the effect of locking in reserves, on planning unit selection frequency. We also compared (using the same statistics) the dissimilarity between solutions based on changes in the compatibility matrix, for the same scenarios (Table 4).

\section{Species models and representation targets}

Targets were based on the threat status of 117 species set by the PROBIO priority setting workshop (Brasil 2007) using the output of MAXENT species distributions probability, (Phillips et al. 2006). We adjusted these targets to enhance complementarity between zones and account for the differential contribution expected from each of the BR zones, using the zone contribution weights. The predicted distribution maps were based on relations between occurrences (presence-only) and several predictive variables: elevation, vegetation, soils, distance to rivers, distance to roads, and fragility. We chose a $70 \%$ threshold for the likelihood of occurrence (Figure 3) as our cut-off point to generate the presence maps analysed by MARXAN.

\section{Comparison between ad hoc and systematically zoned Biosphere Reserves}

Finally we compared the target achievement of the ad hoc scenario (the existing allocation of BR zones) to target achievement from systematic zoning. This step is essential in systematic planning and provides evaluation starting point in cases where reserves and indigenous land were already designated (Pressey 1994). The existing spatial configuration of the PBR (ratified by UNESCO in 2000) was compared with the best solution for 1000 runs of MARXAN for all scenarios, each with 1,000,000 interations.
We used the same targets for the ad hoc PBR (baseline scenario) as the ones explained for scenarios (5) and (6). We then illustrated the possibilities offered by the software to support the development of new BR proposals, improve the design of existing BRs and compare alternative spatial configurations based on the tradeoffs between objectives.

\section{Our Findings}

We present the results for all scenarios but choose scenarios (5) and (6) to illustrate the difference in outcomes between a systematically designed BR in the Pantanal when compared to the PBR design proposed to UNESCO in 2000 (Figure 4 $\mathrm{e}, \mathrm{f} \& \mathrm{~g})$. While acknowledging the importance of the PBR as a tool for watershed management, land use ordination and stakeholder engagement, the current PBR lacks a defensible framework and needs a systematic review of its zonation scheme.

\section{Target achievement}

Our results for feature targets show that $82 \%$ of all 293 features in scenario (5) reached their respective targets. In scenario (6) where reserves were locked in, $84 \%$ of overall targets were achieved showing no distinctive difference between scenarios (5) and (6), in overall target achievement for the single best solution of each scenario. We set targets in two different ways, first using the overall feature target and second using feature-by-zone targets. In both cases the representation target was considered adequately achieved when $90 \%$ of the target was reached.

Feature representation was fully achieved in both scenarios for wildlife densities (marsh deer, pampas deer, caimans and capybaras) and watersheds. The targets were also achieved for cattle densities and distance to roads and rivers, which are associated with land value and the sustainability of properties within PBR planning units (Lourival et al. 2008).

In Table 5 we showed a comparison between scenarios ( 1 to 6 ) in regards to under-representation. Scenario (5) had one vegetation class, two vegetation subclasses and one soil type under-represented (with respectively $83,77,61$ and $87 \%$ achievement). While the scenario (6) under-represented

Table 4. Comparison between scenarios (5) and (6) for missed targets by zone. The number in [ ] represents the overall number of features targeted for all zones. We show the number of targets that did not reach $90 \%$ representation, the average (avg) proportion of their achievements and their standard deviation.

\begin{tabular}{llccccc}
\hline & Targets by zone & $\begin{array}{c}\text { All zones } \\
\text { combined }\end{array}$ & Available & Transition & Buffer & Core \\
\hline Scenario (5) & Missed (n=35) & 0.31 & 0.09 & 0.17 & 0.40 & 0.34 \\
{$[112]$ no } & Avg. achievement & 0.61 & 0.46 & 0.64 & 0.32 & 0.34 \\
reserves & Standard deviation & 0.36 & 0.23 & 0.21 & 0.29 & 0.28 \\
& Variance & 0.13 & 0.05 & 0.04 & 0.08 & 0.08 \\
Scenario (6) & Missed (n =33) & 0.29 & 0.12 & 0.06 & 0.33 & 0.48 \\
{$[114]$ reserves } & Avrg. achievement & 0.73 & 0.50 & 0.52 & 0.67 & 0.49 \\
locked in & Standard deviation & 0.28 & 0.24 & 0.29 & 0.17 & 0.27 \\
& Variance & 0.08 & 0.06 & 0.08 & 0.03 & 0.07 \\
\hline
\end{tabular}




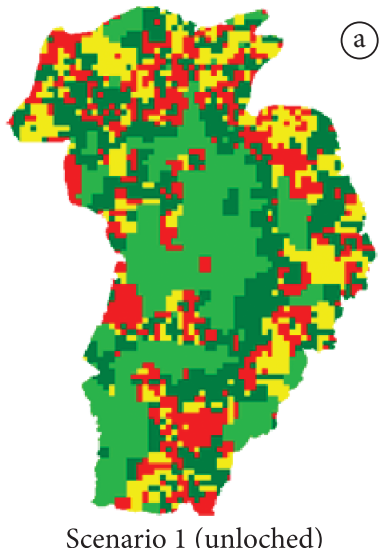

Scenario 1 (unloched)

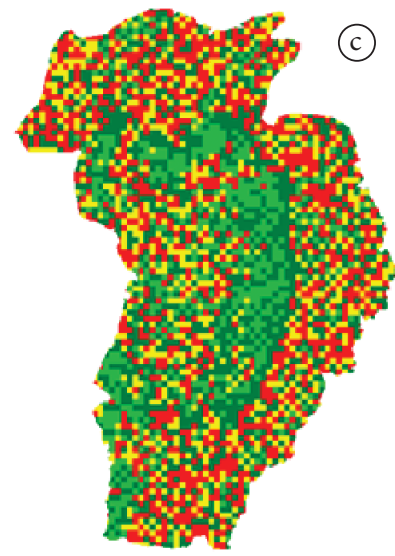

Scenario 3 (unloched)

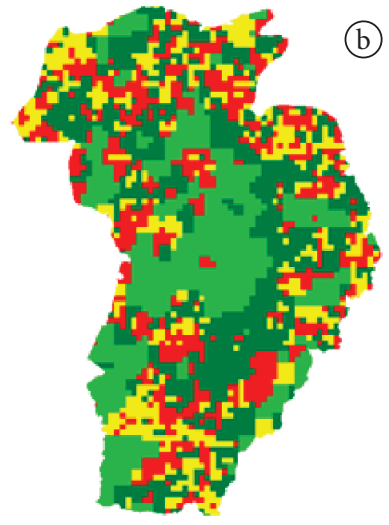

Scenario 2 (loched)

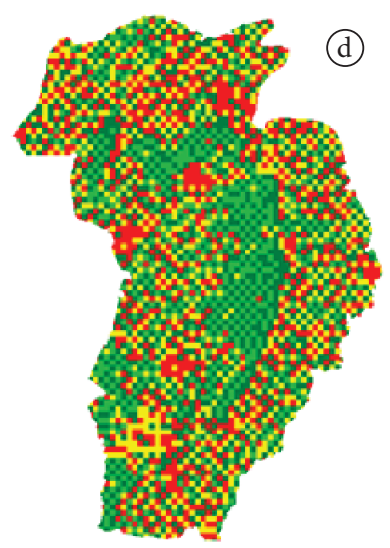

Scenario 4 (loched)

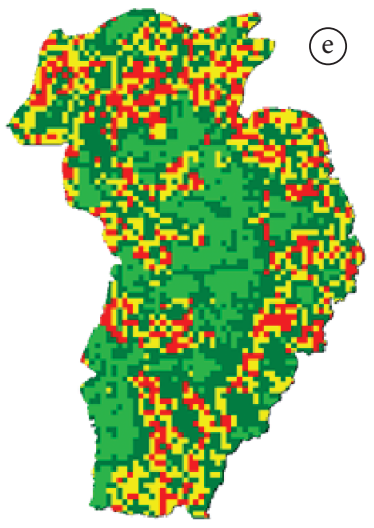

Scenario 5 (unloched)

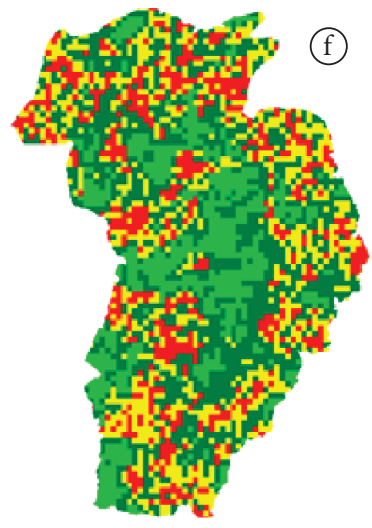

Scenario 6 (loched)

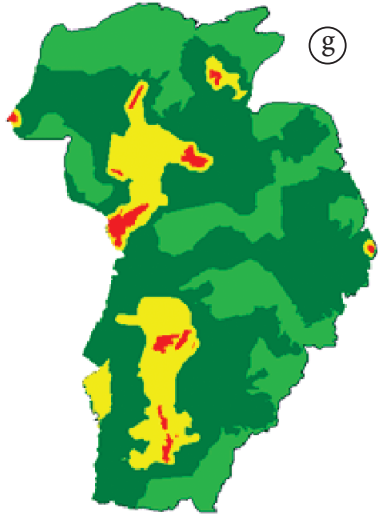

Ad hoc scenario

Figure 4. Maps representing the best solution of Marxan with Zones, for all scenarios (1 to 6) plus the ad hoc scenario as specified in Table 5. The core areas (red), buffer zones (yellow) and transition zones (dark green). Here the transition zone planning units are split into dark green (irreplaceable) and light green as planning units that are part of the planning area but do not contribute or were not necessary for target achievement. 


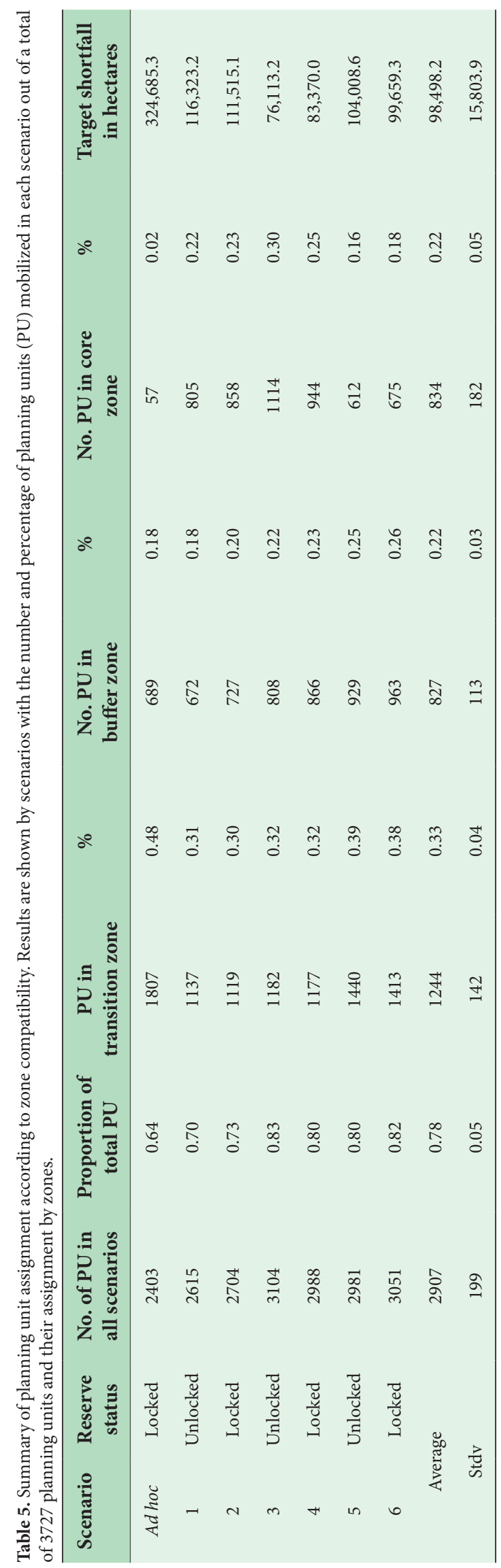


one freshwater eco-domain, one vegetation subclass and one soil type (with respectively 73,81 and $56 \%$ achievement). The soil type and one of the under-represented vegetation subclasses were common to both scenarios.

\section{Species models and representation targets}

In the solutions proposed by MARXAN with Zones, full representation was achieved in scenario (5) for $62 \%$ of species, while in scenario (6), around $63 \%$ of species were fully represented. The difference in representation between the two scenarios was only in four species. Nevertheless the under-represented species both scenario, had relatively high target achievement (i.e. 78 \& 77\% respectively).

\section{Zone targets}

The possibility of setting targets by zone is what sets apart MARXAN with Zones from the existing systematic planning software. We used this capability to set targets for 32 of the 293 features under analysis, based on UNESCO-MAB guidelines. We chose to target these 32 features directly to particular zones (e.g. indigenous territories assigned to buffer zones in scenario 6). We also wanted to maximize economic sustainability in areas already degraded therefore we spatially targeted deforestation to transition zones.

Overall, scenario (6) missed fewer targets (29\%) and had higher average achievement levels (73\%) for missed targets than scenario (5) with 31 and $61 \%$ respectively for the single best solution. Results were very close in terms of their representation capabilities for zone targets, however what makes them different is the percentage of missed targets for core zones, which was $34 \%$ for the no-reserve scenario and $48 \%$ when reserves were locked in (Table 5), pointing to the inefficiencies of current reserves. Despite those figures, our results for buffer and transition zones showed inverted trend.

\section{Connectivity and spatial configuration zone compatibility (Juxtaposition)}

We tested MARXAN with Zones capacity to generate spatial patterns compatible with the BR model. Our results illustrate the variety of configuration patterns that can be achieved within MARXAN with Zones. The first pattern emerged from scenarios (1) and (2), where we impose complete compatibility between planning units of the same zone and no compatibility between planning units of different zones (as in Table 3). We achieved high levels of spatial aggregation in the overall best solution, as well as in all zones, but no nestedness between zones (Figure 3a,b).

The clumping process showed in each zone transposed the planning unit selection frequency hierarchy where frequently selected planning units occupy the center of clumps while less frequently selected planning units tend to surround them. A discrete increase in planning unit assignment (3\%) was observed when reserves were not locked (scenarios 1) compared to when reserves were locked in the solution (scenario 2). A checkered pattern emerged for scenarios (3) and (4), when complete incompatibility between planning units of the same zone and total compatibility between planning units of distinct zones was imposed (Figure 3c,d). This pattern was broken only for planning units locked in, and the planning units of existing reserves and indigenous territories were clumped.

When we imposed clumping to planning units (scenarios $1 \& 2$ ), the shortfalls were on average 30\% bigger than those in scenarios ( $3 \& 4$ - anti-clumping), however these scenarios ( $3 \& 4$ ) mobilized on average, $10 \%$ more planning units. When compared the difference in shortfalls between scenarios ( $1 \& 3$ ) was reduced by $34 \%$ while between ( 2 \& 4) the reduction of shortfall was $25 \%$ in both cases (clumped and anti-clumped). Allowing the software to choose freely, without the constraint of existing reserves, improved target achievement.

In scenarios (5) and (6) we defined the compatibility matrix with properties common to both sets of scenarios ( $1 \& 2$ ), and ( $3 \& 4)$. We aimed to generate flexible nestedness by allowing planning units of the same zone to be compatible between them and increased incompatibility hierarchically between zones. The pair wise compatibility matrix showed for example that core zones are more compatible with buffer zones than with transition zones. The results (Table 5) showed an average increase in planning unit assignment of $13.5 \%$ between scenarios ( 1 \& 2), and scenarios (5 \& 6 ), while there was no significant increase between ( $3 \&$ $4)$, and (5 \& 6).

However the planning units' assignment to each zone between the above sets of scenarios varied dramatically (Table 5). It is worth noticing that the amount of planning units assigned to core zones varied from 16 and $18 \%$ of all planning units in scenarios (5) and (6), to 30 and $25 \%$ in scenarios (3) and (4).

The sensitivity of this procedure can be explored through several combinations of compatibility values, which can be used to increase efficiency by assigning planning units to different zones. The scenarios proposed engaged between 70 and $83 \%$ of all planning units of the UPRB watershed, the remainder (30 and 17\%) being composed of planning units that are not necessary to achieve the representation requirements because of cost and/or lack of features.

\section{Key issues for Discussions about Biosphere Reserve Desing}

Zoning has been society's mechanism for organizing the use of land and managing the spatial components of population growth. Through zoning society is able to reduce conflicts between land users via agreed compromises (Werner 1926; Bojorquez-Tapia et al. 2004). So far zoning has been used 
as a spatial tool in urban planning (Conway \& Lathrop 2005), tourism, industry and forestry with relative success (Bos 1993). However, the conservation literature lacks examples, methods and applications of spatially explicit, multi-objective and multi-stakeholder zonation schemes.

Despite the established literature and the proven advantages of systematic planning to conservation (Pressey 1994; Margules \& Pressey 2000; Bojorquez-Tapia et al. 2003), Biosphere Reserves continue to be designed using ad hoc configuration approaches (Dyer \& Holland 1991; Pressey \& Tully 1994). For that reason the capacity to demonstrate that BR can spatially represent environmental, cultural and economic sustainability requirements remains elusive. Defining the role and contribution of each of the BR zones towards these objectives has been a point of discussion for some time (Tangley 1988). Very little has been done to quantitatively account for the social, biodiversity and sustainability functions of BR (Price 1996).

We believe, however, that this is the appropriate time to advocate the case of systematic zoning for Biosphere Reserves, considering the timeframe set in the Madrid Action Plan (MAB Program 2008) whereby all BRs need their zonation to be reviewed by 2013. Our intention is to contribute to the evaluation process of Biosphere Reserves in general and the rezoning of the Pantanal BR. Our results showed that the current design of the PBR not only under-represents the biodiversity objectives but also ignores the other two essential components of a BR, the protection of local cultures and the economic sustainability of the region.

Biosphere Reserves are an interesting platform to develop systematic zoning applications, since they were conceived under a multi-objective, multiple-zone and multiple-cost framework. Although some studies discussed the qualitative characteristics of BR (Kellert 1986; Tangley 1988; Batisse 1990; Solecki 1994), so far few studies evaluated their quantitative characteristics (Howard et al. 1997; Lourival et al. 2009). Dyer \& Holland (1991) emphasized the lack of clear definitions and tangible goals for BRs, to take into account the importance of ecological processes, complementarity, connectivity and comprehensiveness of BR networks. We demonstrate that systematic zoning can fulfill such gaps while optimizing compromises between conflicting objectives in a spatially explicitly manner.

\section{Reaching targets at the}

\section{ad hoc vs. systematically designed biosphere} reserves

Our results have demonstrated the effectiveness of a BR can dramatically increase when they are systematically designed. The PBR does not meet a large number of its targets and would need to reassign at least 300,000 ha in planning units to achieve all targets (Table 5). When compared with systematically designed PBR (using the same targets and costs), shortfalls were reduced to less than 100,000 ha, maintaining efficiency. Although increases in penalties for under-representing features could bring MARXAN solutions close to full representation (Figure 7).

Systematically planned BRs provide guidance to the spatial allocation of planning units in order to achieve the desired feature representation, now that all zones have to contribute equally towards BR objectives. This directive can improve the flexibility of BRs offering opportunities for improvement during the review process of BRs, scheduled for 2013 (MAB Program 2008). Enhancing and expanding our understanding of feature contributions to each zone, and the eventual use of floating targets (which may vary between zones), would allow BRs to simultaneously balance comprehensiveness and complementarity between zones, while improving their overall efficiency, becoming a major showcase for landscape scale planning.

\section{Efficiency in Biosphere Reserves}

Even though the tradeoffs between comprehensiveness and efficiency are not evaluated in depth here, a substantial increase in number of planning units selected was observed between ad hoc and systematically designed scenarios (Figure 7). It is our understanding that targets need to be appropriately revisited to adequately reflect population requirements and species densities in accordance to different land use regimes, and for that reason regulated by the zone restriction procedures.

The concept of efficiency commonly used in systematic conservation planning, (Pressey and Nicholls 1989), needs to be adjusted in BRs to tackle the particularities associated with zoning. A slight modification in the way efficiency is normally calculated allows planners to integrate the effects of multiple ownership in off-reserve conservation (Lourival et al. 2009). A specific example was the planning unit assignments to core areas (i.e. to become IUCN categories I to IV) in the Pantanal Biosphere Reserve, which will need to be increased by more than one order of magnitude (Figure $6 \mathrm{c} \& \mathrm{~d}$ ). Moreover, if planners want to achieve the proposed targets, buffer zones would have to almost double, while transition zones need to be reduced. Nonetheless, the results for target achievement are just an illustration of the advantages and possibilities of MARXAN with Zones. If full feature representation was imperative several parameters in the software could be adjusted to do so, either via the target per zone or overall target.

Some other measures of performance regularly applied to conservation planning, can also be used for systematic zoning. As an example we used the simple system of classifying planning units according to their selection frequency (Stewart et al. 2003). This method, was expanded in (Lourival et al. 2009), and can be used to classify planning units for all zones. 
1) Scenario 1 (unlocked)

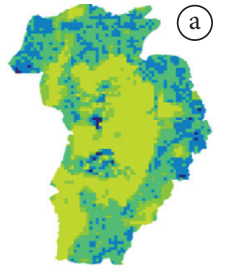

Core

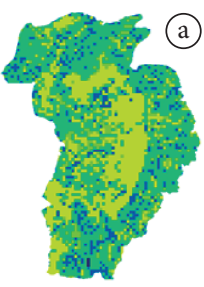

Core

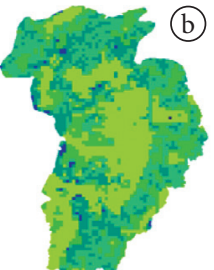

Buffer

3) Scenario 3 (unlocked)

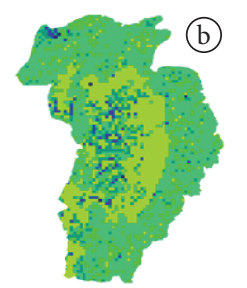

Buffer

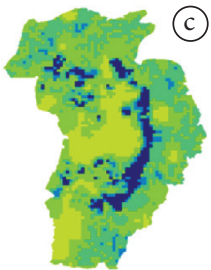

Transition

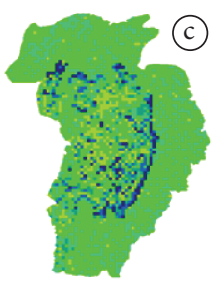

Transition

5) Scenario 5 (unlocked)

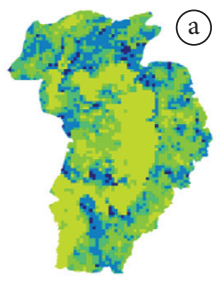

Core

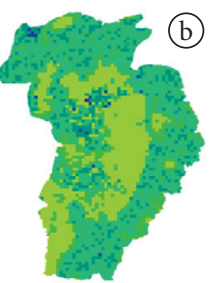

Buffer

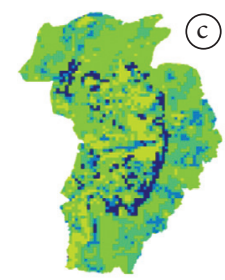

Transition

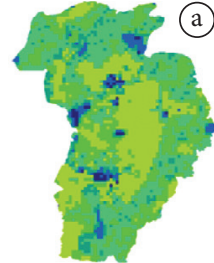

Core

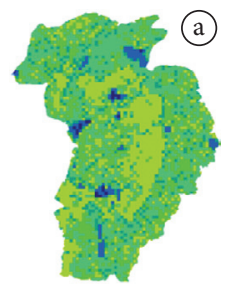

Core

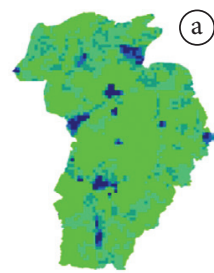

Core

2) Scenario 2 (locked)

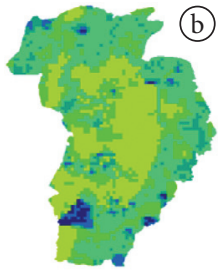

Buffer

4) Scenario 4 (locked)

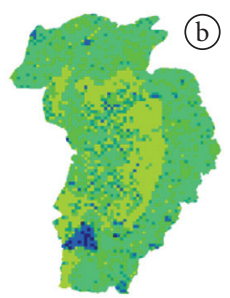

Buffer

6) Scenario 6 (locked)

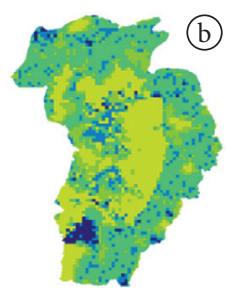

Buffer

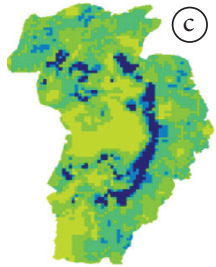

Transition

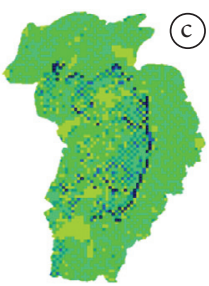

Transition

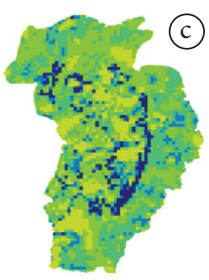

Transition

Figure 5. Variation in selection frequency of planning units respectively to core, buffer and transition zones of the Pantanal Biosphere Reserve classified by grades of one standard deviation unit, from low (yellow) to high (dark blue) selection frequency for each scenario compared in Table 6.

The selection frequencies shown in one standard deviation intervals can be used to guide the priority of zone implementation based on selection frequency. Our approach suggests a large expansion in the core zones (see Figure 6a,b) maybe politically unpalatable. Market-based methods such as legal reserve compensation (Lourival et al. 2008) and other incentives may be the best way to achieve the expansion in the core zone rather than acquisition.

\section{The issue of zone compatibility \& juxtaposition}

The spatial configurations generated by MARXAN with Zones offer greater flexibility for the decision-making process, allowing a variety of scenarios and configurations, which can fulfill the BR objectives. Two emergent properties became important in systematic zoning, modulating the compatibility between zones. The first can be called permissibility and involves the level of acceptable use of a planning unit that that does not compromise its zone objectives. The second property is zone juxtaposition which defines the spatial compatibility between zones. Together they enable us to isolate threatening processes from sensitive areas, create connectivity and allow spreading or clumping of zones.
Overall, the best solution for scenarios (5) and (6) illustrates well the principle of flexible nestedness proposed by the Madrid Action Plan. Under these new guidelines the "egg model" originally prescribed for BR (Figure 1) become amenable to embrace alternative spatial configurations and respond to design limitations. Exploring the sensitivity of the compatibility matrix for intermediate scenarios (5 \& 6) illustrates the capacity of the compatibility matrix to influence implementation costs and the efficiency of the $\mathrm{BR}$, by assigning fewer planning units to core zones, but compensating in other zones when applicable.

\section{Our Conclusions}

We demonstrated the applicability and flexibility of MARXAN with Zones to Biosphere Reserves systematic planning. We showed that socio-cultural objectives can be explicitly optimized and represented across all zones in the same way biodiversity and economic objectives can. In addition we illustrated, in a variety of spatial configurations, the tradeoffs between feature representation and efficiency for the BR (Table 2). 

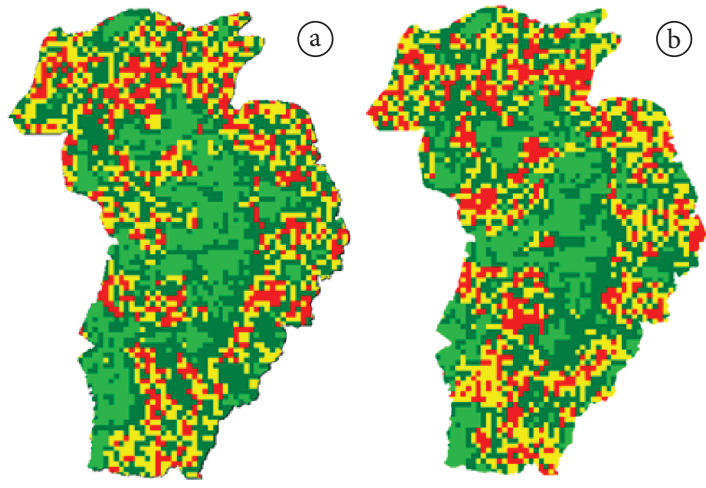

Scenario 5

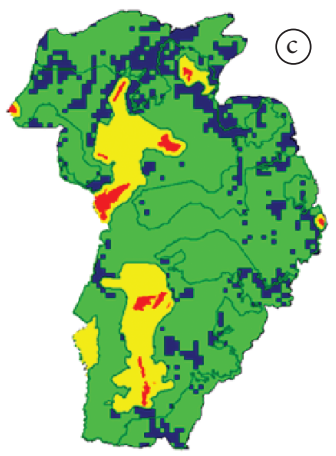

Scenario 5

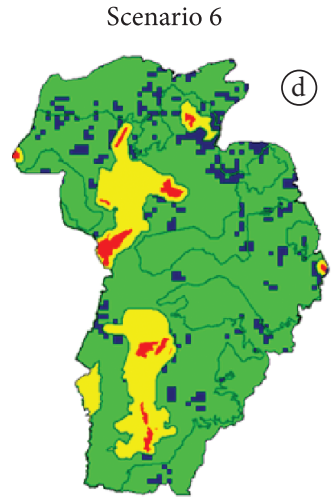

Scenario 6

Figure 6. Limit of the Upper Paraguay River Basin (green), map (a) represents scenario 5 where reserves are not locked in the solution and map (b) shows scenario 6 with the reserves locked in. Those are the best solutions of Marxan with Zones for the Pantanal Biosphere Reserve; in (red) are the core areas, in (yellow) the buffer zones and in (dark green lines) the transition zone. The blue areas below are frequently selected planning units for core zones in scenarios 5 (a) and 6 (b). These are the necessary increments for core zones for the PBR to aim at the preset core zone targets. The overlapped figure represented in yellow (buffer) and red (core) and dark green line (transition) are placed to mask what increases are necessary in zones previously considered as transition areas.

An emergent property of the comparison between the ad hoc PBR and systematically planned alternatives was that, despite the spatial configuration of zones and the diversity of scenarios, the variability in the percentage of planning units assigned to each one of the three BR zones was fairly constant. On average, systematically designed core zones used $22 \%$ of all planning units ( $S D=5 \%$ ), buffer zones occupied also 22\% (3\%) and transition zones 33\% $(\mathrm{SD}=4 \%)$ of all planning units to represent targets. The ad hoc PBR had $2 \%$ of planning units in core areas, $18 \%$ in buffer zones and $48 \%$ in transition zones (Table 5). The systematically designed BRs assigned $23 \%$ of planning units to available, either because they did not contribute to targets or because they were too expensive to be included. In the ad hoc PBR the class of planning units available accounted for $30 \%$ of the watershed for no explicit reason, we chose to add them to the Transition zone (summarized in Table 5), since they represent no acquisition cost, and provide a sense of watershed based management, which ultimately will be the source of income to the BR, through its catchment authority.

Considering that the MAB program has no guidelines for quantifying the amount of the planning region to be allocated to each zone, our systematic approach for the Pantanal Biosphere Reserve provides an interesting insight into how much of the region needs to be in different zones i.e.; $22 \pm 5 \%$ in core zones (e.g. IUCN I to IV), $22 \pm 3 \%$ in buffer and $33 \pm 4 \%$ in transition zones, in order to efficiently enhance target (i.e. objectives) achievements.

UNESCO conceived BRs to support sustainable societies but, until now, it was unable to quantify their performance against the desired objectives. It is clear, that protected areas alone cannot guarantee those objectives. Systematically zoned BRs are an amenable alternative to reach such objectives (Figure 7).

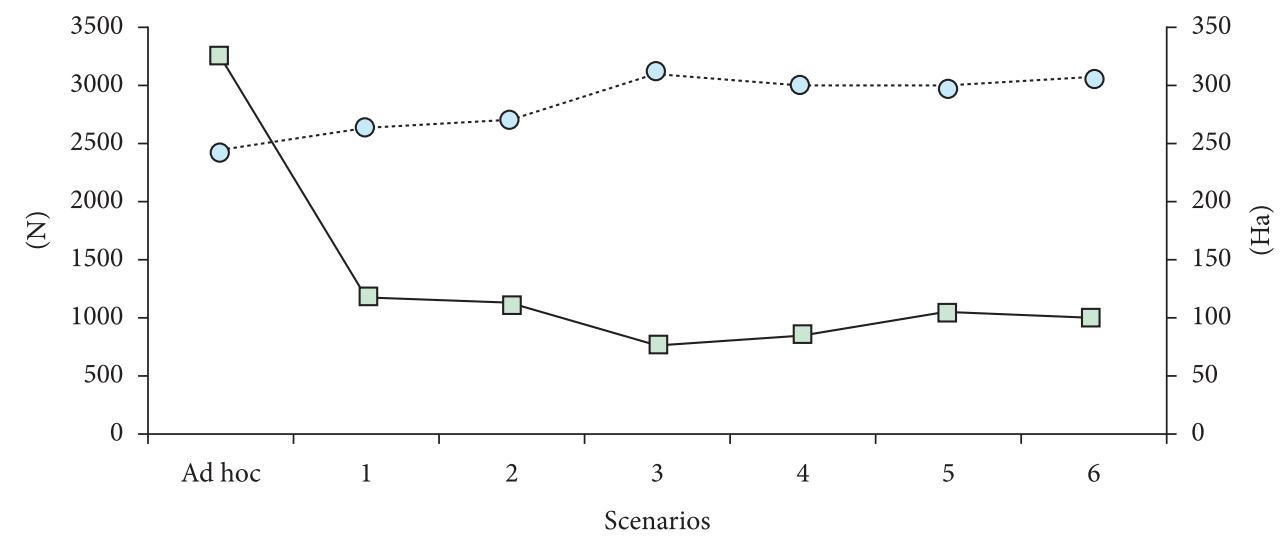

Figure 7. Comparison between ad hoc and systematically designed Pantanal Biosphere Reserve, the graph represents the relationship between number of planning unit engaged in each scenario and the shortfall measured in hectares for all targets. 


\section{Acknowledgements}

We like to thanks to The Capes Foundation - Ministry of Education - Brazil and The Commonwealth Environmental Research Facilities-AEDA for providing the funds for this study. We also thank Dr. Gordon Grigg and our colleagues of the spatial ecology lab from the University of Queensland for their support and constructive criticism. Special thanks for Leonie Seabrook, Peter Baxter and Ché Elkin for revising the manuscript.

\section{References}

Assine ML \& Soares PC, 2004. Quaternary of the Pantanal, west-central Brazil. Quaternary International, 114:23-34. http://dx.doi.org/10.1016/S1040-6182(03)00039-9

Ball IR \& Possingham HP, 2000. MARXAN v1.8.6 Marine Reserve Design; using Spatially Explicit Annealing. Available from: <www.uq.edu.au/MARXAN/>.

Batisse M, 1990. Development and Implementation of the Biosphere Reserve Concept and Its Applicability to Coastal Regions. Environmental Conservation, 17(2):111-116. http:// dx.doi.org/10.1017/S0376892900031878

Batisse M, 1997. Biosphere reserves - A challenge for biodiversity conservation \& regional development. Environment, 39(5):6-9. http://dx.doi.org/10.1080/00139159709603644

Bojorquez-Tapia LA et al., 2003. Mapping expert knowledge: Redesigning the Monarch Butterfly Biosphere Reserve. Conservation Biology, 17(2):367-379. http://dx.doi. org/10.1046/j.1523-1739.2003.01309.x

Bojorquez-Tapia LA et al., 2004. Environmental conflicts and nature reserves: redesigning Sierra San Pedro Martir National Park, Mexico. Biological Conservation, 117(2):111-126. http://dx.doi.org/10.1016/S0006-3207(03)00265-9

Bos J, 1993. Zoning in Forest Management: a Quadratic Assignment Problem Solved by Simulated Annealing. Journal of Environmental Management, 37(2):127-145. http://dx.doi.org/10.1006/jema.1993.1010

Brasil. Ministério do Meio Ambiente - MMA, 1999. Ações Prioritárias para a Conservação da Biodiversidade do Cerrado e Pantanal. Brasília: MMA, PROBIO. 27 p.

Brasil. Ministério do Meio Ambiente- MMA, 2007. Áreas prioritárias para a conservação, uso sustentável e repartição de benefícios da biodiversidade brasileira. Biodiversidade, n. 31. Available from: <www.mma.gov.br/portalbio $>$.

Cabeza M et al., 2004. Combining probabilities of occurrence with spatial reserve design. Journal of Applied Ecology, 41(2):252-262.

Cabeza M \& Moilanen A, 2006. Replacement cost: A practical measure of site value for cost-effective reserve planning. Biological Conservation, 132(3):336-342. http://dx.doi. org/10.1016/j.biocon.2006.04.025

Carwardine J et al., 2007. Conservation planning with irreplaceability: does the method matter? Biodiversity and Conservation, 16(1):245-258. http://dx.doi.org/10.1007/ s10531-006-9055-4
Conway TM \& Lathrop RG, 2005. Alternative land use regulations and environmental impacts: assessing future land use in an urbanizing watershed. Landscape and Urban Planning, 71(1):1-15. http://dx.doi.org/10.1016/j. landurbplan.2003.08.005

Crawshaw PG \& Quigley HB, 1991. Jaguar Spacing, activity and habitat use in a seasonally flooded environment in Brazil. Journal of Zoology, 223:357-370. http://dx.doi. org/10.1111/j.1469-7998.1991.tb04770.x

Daoust RJ \& Childers DL, 1999. Controls on emergent macrophyte composition, abundance, and productivity in freshwater everglades wetland communities. Wetlands, 19(1):262-275. http://dx.doi.org/10.1007/ BF03161756

Dasmann RF, 1988. Biosphere Reserves, Buffers and Boundaries. Bioscience, 38(7):487-489. http://dx.doi.org/10.2307/1310953

DeAngelis DL et al., 1998. Landscape modeling for everglades ecosystem restoration. Ecosystems, 1(1):64-75. http://dx.doi. org/10.1007/s100219900006

Dhargalkar VK \& Untawale AG, 1991. Marine Biosphere Reserves - Need of the 21st-Century. Journal of Environmental Biology, 12:169-177.

Dyer MI \& Holland MM, 1991. The Biosphere-Reserve Concept - Needs for a Network Design. Bioscience, 41(5):319-325. http://dx.doi.org/10.2307/1311585

Elith J et al., 2006. Novel methods improve prediction of species distributions from occurrence data. Ecography, 29(2):129 151. http://dx.doi.org/10.1111/j.2006.0906-7590.04596.x

Field SA et al., 2004. Minimizing the cost of environmental management decisions by optimizing statistical thresholds. Ecology Letters, 7(8):669-675. http://dx.doi. org/10.1111/j.1461-0248.2004.00625.x

Gaston KJ \& Rodrigues ASL, 2003. Reserve selection in regions with poor biological data. Conservation Biology, 17(1):188 195. http://dx.doi.org/10.1046/j.1523-1739.2003.01268.x

Gerber LR et al., 2003. Population models for marine reserve design: A retrospective and prospective synthesis. Ecological Applications, 13(1):S47-S64. http://dx.doi. org/10.1890/1051-0761(2003)013[0047:PMFMRD]2.0.CO;2

Higgins JV et al., 2005. A freshwater classification approach for biodiversity conservation planning. Conservation Biology, 19(2):432-445. http://dx.doi. org/10.1111/j.1523-1739.2005.00504.x

Higgins JV et al., 2004. Beyond Noah: saving species is not enough. Conservation Biology, 18(6):1672-1673. http:// dx.doi.org/10.1111/j.1523-1739.2004.0421b.x

Howard P et al., 1997. Planning conservation areas in Uganda’s natural forests. Oryx, 31(4):253-264. http:// dx.doi.org/10.1017/S0030605300022213

Junk WJ \& Nunes da Cunha C, 2005. Pantanal: a large South American wetland at a crossroads. Ecological Engineering, 24(4):391-401. http://dx.doi.org/10.1016/j. ecoleng.2004.11.012

Kellert SR, 1986. Public understanding and appreciation of the Biosphere Reserve concept. Environmental 
Conservation 13(2):101-105. http://dx.doi.org/10.1017/ S0376892900036687

Loiselle BA et al., 2003. Avoiding pitfalls of using species distribution models in conservation planning. Conservation Biology, 17(6):1591-1600. http://dx.doi. org/10.1111/j.1523-1739.2003.00233.x

Lourival R et al., 2008. Getting fourteen for the price of one! Understanding the factors that influence land value and how they affect biodiversity conservation in central Brazil. Ecological Economics, 67(1):20-31. http://dx.doi.org/10.1016/j. ecolecon.2008.04.022

Lourival R et al., 2009. A systematic evaluation of the conservation plans for the Pantanal wetland in Brazil. Wetlands 29(4).

MAB Program, 2008. The Madrid action plan 2008 - 2013. In: Proceedings of the $3 r d$ Wolrd Congress of Biosphere Reserves and 20th session of the International Coordinating Council of the MAB Programme, 2008; Madrid. UNESCO.

Margules CR \& Pressey RL, 2000. Systematic conservation planning. Nature, 405:243-253. PMid:10821285. http:// dx.doi.org/10.1038/35012251

Moilanen A et al., 2005. Prioritizing multiple-use landscapes for conservation: methods for large multi-species planning problems. Proceedings of the Royal Society B-Biological Sciences, 272(1575):1885-1891. PMid:16191593. PMCid:1559892. http://dx.doi.org/10.1098/rspb.2005.3164

Monserud RA \& Leemans R, 1992. Comparing global vegetation maps with Kappa statistics. Ecological Modelling, 62:275-293. http://dx.doi.org/10.1016/0304-3800(92)90003-W

Mourão GM et al., 2000. Aerial surveys of caiman, marsh deer and pampas deer in the Pantanal Wetland of Brazil. Biological Conservation, 92(2):175-183. http://dx.doi. org/10.1016/S0006-3207(99)00051-8

Mourão GM et al., 1994. Test of an Aerial Survey for Caiman and Other Wildlife in the Pantanal, Brazil. Wildlife Society Bulletin, 22(1):50-56.

Negi CS \& Nautiyal S, 2003. Indigenous peoples, biological diversity and protected area management - policy framework towards resolving conflicts. International Journal of Sustainable Development and World Ecology, 10(2):169-179.

Odum WE et al., 1995. Natures Pulsing Paradigm. Estuaries, 18(4):547-555. http://dx.doi.org/10.2307/1352375

Padovani CR et al., 2004. Desmatamento do Pantanal brasileiro para o ano de 2000. In: Anais do IV Simpósio de Recursos Naturais e Sócio-econômicos do Pantanal, Sustentabilidade Regional, 2004; Corumbá. Corumbá: Embrapa/CPAP.

Phillips SJ et al., 2006. Maximum entropy modeling of species geographic distributions. Ecological Modelling, 190(3-4):231259. http://dx.doi.org/10.1016/j.ecolmodel.2005.03.026

Poore D, 1995. Unesco-International-Conference on Biosphere Reserves, held in Seville, Spain, During 20-25 March 1995. Environmental Conservation, 22(2):186-187. http://dx.doi. org/10.1017/S0376892900010389

Possingham HP et al., 2000. Mathematical Methods for identifying representative reserve networks. In: Ferson S \& Burgman MA (eds). Quantitative Methods for Conservation
Biology. New York: Springer-Verlag. p. 291-305. http:// dx.doi.org/10.1007/0-387-22648-6_17

Possingham HP, 2001. Models, problems and algorithms: perceptions about their application to conservation biology. MODSIM.

Possingham HP et al. 2006. Protected Areas: Goals, Limitations, and Design. In: Groom MJ, Meefe GK \& Carroll CR (eds). Principles of Conservation Biology. Sunderland: Sinauer Associates. p. 691-700.

Pressey RL, 1994. Ad Hoc reservations - forward or backward steps in developing representative reserve systems. Conservation Biology, 8(3):662-668. http://dx.doi. org/10.1046/j.1523-1739.1994.08030662.x

Pressey RL, 1999. Systematic conservation planning for the real world. Parks, 9(1):1-5.

Pressey RL \& Nicholls AO, 1989. Efficiency in Conservation Evaluation - Scoring Versus Iterative Approaches. Biological Conservation, 50(1-4):199-218. http://dx.doi. org/10.1016/0006-3207(89)90010-4

Pressey RL \& Taffs KH, 2001. Scheduling conservation action in production landscapes: priority areas in western New South Wales defined by irreplaceability and vulnerability to vegetation loss. Biological Conservation, 100(3):355-376. http://dx.doi.org/10.1016/S0006-3207(01)00039-8

Pressey RL \& Tully SL, 1994. The Cost of Ad Hoc Reservation - a Case-Study in Western New-South-Wales. Australian Journal of Ecology, 19(4):375-384. http://dx.doi. org/10.1111/j.1442-9993.1994.tb00503.x

Price MF, 1996. People in biosphere reserves: an evolving concept. Society \& Natural Resources, 9(6):645-654. http:// dx.doi.org/10.1080/08941929609381002

ReVelle CS et al., 2002. Counterpart models in facility location science and reserve selection science. Environmental Modeling \& Assessment, 7(2):71-80. http://dx.doi. org/10.1023/A:1015641514293

Rosova V, 2001. Biosphere reserves: Model territories for sustainable development. Ekologia-Bratislava, 20:62-67.

Sabatini MDC et al., 2007. A quantitative method for zoning of protected areas and its spatial ecological implications. Journal of Environmental Management, 83:68-76.

Schoemaker PJH, 1991. The quest for optimality - a positive heuristic of science. Behavioral and Brain Sciences 14(2):205214. http://dx.doi.org/10.1017/S0140525X00066140

Solecki WD, 1994. Putting the biosphere reserve concept into practice - some evidence of impacts in rural communities in the United-States. Environmental Conservation, 21(3):242247. http://dx.doi.org/10.1017/S0376892900033221

Stewart RR et al., 2003. Opportunity cost of ad hoc marine reserve design decisions: an example from South Australia. Marine Ecology-Progress Series, 253:25-38. http://dx.doi. org/10.3354/meps 253025

Tangley L, 1988. A New Era for Biosphere Reserves - Mexicos Sian Kaan Shows That Its Hard to Be Everything a Biosphere Reserve Should Be. Bioscience, 38(3):148-155. http://dx.doi. org/10.2307/1310446 
Ukeles JB, 1964. The consequences of municipal zoning. Washington: Urban Land Institute.

UNESCO, 1995. The Seville Strategy for Biosphere Reserves. Nature \& Resources, 31(2):2-17.

UNESCO 2002. Biosphere Reserves - Special places for people and nature. S. a. C. O. United Nations Educational. Quetigny France, United Nations Educational, Scientific and Cultural Organization.

UNESCO, 2007. Biosphere Reserves - World Network. Paris: UNESCO. $21 \mathrm{p}$.

Veneziani P et al., 1998. Map of erodibility classes of part of Taquari River Basin, based on TM-Landsat images. Pesquisa Agropecuaria Brasileira, 33:1747-1754.

Verdiell A \& Sabatini MC, 2005. A mathematical model for zoning protected natural areas. International Transactions in Operational Research, 12(2):203-213. http://dx.doi. org/10.1111/j.1475-3995.2005.00498.x
Wallington TJ et al., 2005. Implications of current ecological thinking for biodiversity conservation: A review of the salient issues. Ecology and Society 10(1).

Wantzen KM, 2003. Cerrado streams - characteristics of a threatened freshwater ecosystem type on the Tertiary Shields of Central South America. Amazoniana 17(3-4):481-502.

Watts ME et al., 2009. MARXAN with Zones: Software for optimal conservation based land- and sea-use zoning. Environmental Modelling \& Software, 24(12):1513-1521. http://dx.doi.org/10.1016/j.envsoft.2009.06.005

Werner HM, 1926. The constitutionality of zoning regulations. Urbana: University of Illinois Press.

West P et al., 2006. Parks and peoples: The social impact of protected areas. Annual Review of Anthropology, 35:251-277. http://dx.doi.org/10.1146/annurev.anthro.35.081705.123308

Wilson KA et al., 2010. Conserving biodiversity in production landscapes. Ecological Applications, 20(6):1721-1732. PMid:20945770. http://dx.doi.org/10.1890/09-1051.1

Received: August 2011 First Decision: September 2011 Accepted: November 2011 